The exhibition of the Jevons manuscripts and correspondence has been made possible by the kindness of his son and daughter, Mr. H. S. Jevons and Miss H. W. Jevons. Mrs. Eleanor Marquand Delanoy gave permission for the use of her father's manuscripts, and Dr. Tyson, librarian of the University of Manchester, allowed the use of the Christie Library for the exhibition.

\section{TRANSPORT IN GREAT BRITAIN}

IN a paper on "The Troubles of Transport", read 1 on September 9 to Section $F$ (Economics) of the British Association at the recent meeting in Belfast, Prof. C. F. Carter (professor of applied economics in Queen's University, Belfast) discussed some current problems of road and rail transport in Great Britain. Figures were quoted showing that transport is an expanding activity (thus making adjustment easier); that it is mostly by road; and that 45 per cent of the 'activity' of transport is organized as an ancillary to some other activity. "It is most unlikely," said Prof. Carter, "that the ownership of ancillary vehicles would have developed to this point if it were not an efficient way of organizing transport. There is . . . no evidence that it would be advantageous to break it down. It follows that the possible field for public ownership of the carriage of goods by road is only a minor part of that activity.'"

The discussion of transport problems in the past year, continued Prof. Carter, has been concentrated on organization and ownership, and has avoided the fundamental issues, which are the relation of charges to costs, the problem of public obligation, and the principles of taxation of road transport.

In theory, the charge for an item of transport should be proportional to the cost of providing an extra unit flow of transport service of that type, when the system has been fully adapted to supply the extra services effectively and conveniently. The ratio of two charges should equal the ratio of costs, taking no account of interest on the cost of 'permanent' assets such as the road bed. The difficulty of costing transport services is very great, and the results must be in part arbitrary. With the railways, enough is known to show that "the present pattern of charges not only bears no relation to costs, but often works the other way". On the road, the difficulty is to find a true economic cost when taxation is so important. Prof. Carter pointed out that "the 'cost' of the roads should for our purposes mean the cost of maintaining and improving them so that next year they can carry traffic as speedily and safely as this year"; with road vehicles increasing in number by 5 per cent per year, this cost would much exceed the sums at present being spent on maintenance. A National Roads Council is needed, charged with the duty of advising on road development and of keeping running estimates for five years ahead of the least expenditure necessary to maintain the roads and to adapt them to expected traffic requirements. Part of the taxation of road vehicles should be segregated as a Roads Tax, paid into a revived Road Fund, which would be autonomous and would carry forward balances from year to year. The Fund should receive what the National Roads Council estimates to be the proper sum to be spent on the roads-whether or not the economic situation allows this amount to be actually spent.
"A more fearsome dragon now lies in our path, called the Public, who are supposed to insist on various uniformities which flatly contradict the principles we have been discussing." Thus rail passenger fares are expected to be proportional to distance, whereas they should be tapered. Uniformity of rates over the whole of a publie organization's system prevents any reflexion of the large differences in cost between different routes. Proposals for dealing with this on the railways were made in Prof. Carter's paper.

After traders have chosen to carry what is convenient to them in their own vehicles, and road hauliers have given preference to profitable traffic, the common carrier by road or rail is left with the odd lots, the awkward cross-country journeys; in particular, the railways are left with precisely the traffics which economically they are least fitted to handle. "If we reject any solution to this problem which involves forcing users to use a particular kind of transport, there seems to me to be only one solution: substantial differential taxation of those parts of transport which have the privilege of choosing their traffic."

The proper taxation of road transport thus has four parts: the general requirements of the Chancellor of the Exchequer ; a tax on petroleum, as long as the state of the balance of payments is deemed more grave than the coal supply; a roads tax; and a levy on those not accepting public obligations.

Towards the end of his paper, Prof. Carter remarked : "I think we need a cooling-off period, to help transport to recover its commercial commonsense after a surfeit of politics; and the best cooler would undoubtedly be a weighty Royal Commission, charged with the duty of giving the whole matter up-to-date and careful study".

\section{SHAPES OF AEROPLANE WINGS}

A PAPER on "The Shape of Wings to Come", by A Mr. D. Keith-Lucas, chief designer of Short Bros. and Harland, Ltd., was read on September 8 before Section G (Engineering) of the British Association at the recent meeting in Belfast. The paper has since been published in full in Engineering $(174,349 ; 1952)$. It is of considerable interest as it goes a long way towards explaining the departures from orthodoxy of wing form which can be seen daily by persons who live near certain airfields.

Mr. Keith-Lucas explains that the main purpose of sweep-back is the reduction and the postponement to higher speeds of compressibility effects normally met with on straight wings at high subsonic speeds. The velocity of the wing relative to the air may be resolved into components normal to and parallel to the span. It is shown that the main aerodynamic effects are fixed by the former, so that the effective air speed of the wing can be made low by the use of sweep. End effects, at the root and the tips of the wing, reduce this benefit by half. It is also shown that at high supersonic speeds the unswept wing can be made efficient again, providing only that it is very thin ; for example, the thickness of the sections may have to be as little as 3 per cent of the chord. Sweepback was first introduced, however, in order to stabilize the all-wing aeroplanes which it was hoped to use before the penalty of severe drag of the 